\title{
AT HOME AND ABROAD
}

\section{Manpower Needs and Medical Education in Nigeria}

\author{
W. R. F. COLLIS,* M.A., M.D., F.R.C.P., F.R.C.P.I., D.P.H. ; T. F. NICHOLSON, $†$ M.B., B.SC., PH.D. \\ I. S. AUDU, $\ddagger$ M.B., M.R.C.P.ED., D.C.H.
}

Brit. med. F., 1966, 1, 792-794

\section{General Picture}

The population of Nigeria has now passed the $50,000,000$ mark and is increasing so rapidly that it may well reach $100,000,000$ in 25 years' time.

There are about 500 Nigerian doctors, of whom nearly half are connected with the two medical schools of Ibadan and Lagos, are in administration, or are on study leave. In addition, there are about 400 foreign doctors in the country. This latter number will probably diminish steadily as the discrepancy in salaries between Nigeria and Europe and America grows.

There are five Ministries of Health in the country-four in the regions and one in Federal Territory of Lagos. None of the Ministries has many more than 100 doctors in the field, so that a territory such as the old Northern Region, with a population around $30,000,000$, has insufficient medical personnel to provide even a skeleton service for the majority of its people.

The doctors themselves in these medical services are frustrated, as it is impossible for a single doctor to supervise a hospital and often ten rural areas, and be physician, surgeon, anaesthetist, prison doctor, and medical officer of health all at once. To be faced by more work than can be carried out in any one day and to know that there is no end to the queue of really sick persons waiting urgently to be seen, plus a pile of paper work which must be dealt with, rapidly leads to failure of morale in anyone exposed to such conditions.

It is generally agreed internationally that any health centre covering the needs of a large urban or rural area requires a basic staff of four doctors if a 24-hour service is to be given and adequate preventive work carried out. No medical service that is not on a 24-hour basis is a genuine service at all.

A great deal of capital, however, has been put into building hospitals, dispensaries, and rural and urban health centres. The opening of quite a number of hospitals thus built has often been delayed for long periods, owing to failure to get doctors. Many more, in fact most, are hopelessly understaffed, having only one or perhaps two doctors, who are expected to do everything day and night, perhaps for a population of 100,000 or more.

The effect of the shortage of doctors is greatly aggravated by lack of properly trained ancillary personnel. Moreover, even if such ancillaries were available the majority of doctors are not trained to supervise them under "field" conditions so that the full benefits of their services will be obtained.

Endemic diseases such as dysentery (both bacillary and amoebic), malaria, trypanosomiasis, onchocerciasis, cerebrospinal fever, and bilharzia are rampant. Epidemics of measles with an overall mortality of $5 \%$ kill thousands of children a year. Tetanus occurs everywhere, with its high mortality and agonizing symptoms, and tuberculosis is a major scourge. Yet

* Professor of Paediatrics, Lagos University Medical School ; Director of Institute of Child Health, Lagos.

t Formerly Professor of Pathology, Lagos University Medical School ; Professor of Chemical Pathology, Toronto Medical School.

$\ddagger$ Associate Professor, Department of Paediatrics, Lagos University Medical School. modern science can now control all these conditions, as is evidenced by the fact that the children of the privileged classes in Nigeria can be completely protected and remain as healthy as children anywhere else.

Underlying every other condition is malnutrition, due to both calorie and protein deficiency. Though poverty is the main contributing cause, it is greatly aggravated by lack of proper dietary knowledge.

\section{Health Service Personnel}

There can be no doubt of the need for a rapid increase in health service personnel. It is obviously of highest priority, for no group of people can be regarded as a modern nation that does not provide a reasonable health service. The deficiency is evident, but the remedy is hard to find. One solution would be to obtain enough doctors to provide at least one practitioner for every 2,000 to 3,000 inhabitants. This, for the present population, means a minimum of 17,000 doctors.

At present there are two medical schools in Nigeria: Ibadan, which has been going for some years and which is now qualifying just over 50 doctors a year, and Lagos, with a present class of 25-28 students just entering the second of their three clinical years. Even if every effort is made by external pressure and superhuman efforts on the part of their staffs, it is unlikely that as many as 2,000 doctors could be qualified by these schools in the next ten years, and it is probable that the population of the country may have increased by $20,000,000$ to a total of over $70,000,000$ by then.

It is evident that it is impossible to provide enough doctors in the next quarter of a century to give anything like the kind of health service now thought to be essential in all the developed countries. What can be done? There is obviously no possibility of meeting this need along orthodox lines.

\section{Second-class Doctors}

One way to meet the need is to shorten the medical course, lower admission and teaching standards, and train a large number of "second-class" doctors. This course has been followed in the past in a number of countries, including Nigeria, but in all areas the results have been unsatisfactory. The graduates from such courses refuse to accept second-class status. The more intelligent leave the service to obtain recognized qualifications. Those with lesser ability agitate constantly for recognition as fully qualified doctors. The result has been that this type of training is being everywhere abandoned.

\section{Ancillary Workers}

If the second-class doctor is ruled out some other type of ancillary workers who can relieve the doctor of a great deal of his work must be trained. Such persons should be technically competent in certain phases of health work and would 
have a relationship to the practising doctor similar to that which the medical laboratory technologist bears to the pathologist. Their basic training might be the same or similar to that of the nurse, but their specialized technical training should be designed to fit them to relieve the doctor of much of the work that at present occupies most of his time but which utilizes only a fraction of his training and skill.

Let us take the example of children. They form the biggest group attending any medical centre in Nigeria to-day. (In the Lagos health centres mothers with their children preponderate in the proportion of $4: 1$.) Many of them are brought by their mothers for minor complaints and problems of feeding and hygiene that can be easily dealt with by a person trained in child management and care who has a limited but practical knowledge of the underlying processes of disease. Such a person should be trained not only to be competent in her special area but to be proud of her ability to recognize those cases which are beyond her skill and about which she needs to consult the doctor. She should also be able to handle the common paediatric emergencies until the doctor arrives. It is the experience of paediatricians running large clinics in Nigeria that out of 500 children not more than 35 to 50 need to be seen by a qualified medical practitioner.

The same principle applies in every other field-midwifery, surgical dressings, general medical complaints. If a corps of such ancillary personnel were trained and then organized in groups under a doctor it would be possible for him to cover a very large population in either town or country. But both the doctor and the ancillary personnel (male and female) would need to have been orientated into this conception. It would also be necessary to train non-medical administrative officers who would be capable of taking most of the office work off the doctor's shoulders. It is clear that such an attitude cannot be expected to be found either in the present trained doctors and nurses or in those now in training.

\section{Need for New Outlook}

A completely new orientation is necessary for medical teachers, and for qualified doctors, nurses, and ancillary personnel, including pharmacists.

So far, practically all the Nigerian doctors have been qualified in medical schools in Western Europe, chiefly Great Britain and Ireland, in America, or, quite recently, in Ibadan. All these schools, including that of Ibadan, which until recently was part of London University, from which the Nigerian doctors have come, have been orientated towards turning out doctors to work where there will be one doctor per 1,000 people. The nurses and pharmacists are similarly orientated. The young Nigerians return expecting to find conditions in Nigeria similar to those in England, and when they find the state of affairs described above they do everything in their power to escape having to do general practice in one of the Government services in Nigeria. Almost without exception they attempt to escape this fate by obtaining some higher qualification which will enable them to specialize or find a post in one of the medical schools, where they can carry on the sort of practice they have been taught that a doctor should expect. The same again applies to the nurses and pharmacists, who tend to resist doing such work as nurses treating patients with minor complaints on their own, or pharmacists pre-packing drugs to be given out by doctors or nurses. It is significant in this respect that some 50 out of the first 60 graduates turned out by the University of Ibadan managed to obtain grants and leave the country so as to obtain high degrees in the United Kingdom in spite of Nigeria's desperate need for doctors.

For this attitude the fault lies partly with the expatriate doctors in the Ministries in the past, and even now in the Universities, who have preferred, and still largely do, to teach along lines they are familiar with and further their own reputa- tions by carrying out interesting, though often academic, research, and partly with the senior Nigerian doctors who have taken over from them in the Ministries and are now reaching leading posts in the Universities. They tend to shut their eyes to the appalling conditions of health pertaining among their own poor.

On the whole the great foundations and aid-programmes have tended to support rather than combat this attitude. Of late, however, a change is becoming apparent. Many Nigerian doctors are beginning to question the present orientation of medicine in Nigeria. The Rockefeller Foundation, with its support for the field work in nutrition on a wide base marrying health and agriculture at Ilesha, and at Igbora with its wide field community health scheme, is making a deep impression on the medical thinking of the day. Indeed, it is partly this work which has made us feel that the time is ripe for a complete, if necessary agonizing, reappraisal of the whole medical situation in Nigeria, followed by a reorientation towards a more realistic attitude to the desperate needs of the people.

\section{Proposals for the Curriculum}

The medical courses will have to be redesigned to fit the new doctors for the part they will be required to play if the new type of health service is to function properly. They will have to learn to function as consultants and directors to a group of ancillaries, to be able and ready to instruct and help them to check their work in a great variety of fields, and to do this without antagonizing or intimidating their ancillary personnel.

This means that the medical student must be introduced to work in the field and the concept of working with and supervising ancillary personnel early in his career. It means that at the same time as he is passing through the discipline of the basic sciences and ward work, where he learns the fundamentals of normal and pathological processes and the methods of honest diagnosis and treatment, he must be learning how to work with and guide those who will be under him. After graduation the young doctor should spend two years in preregistration work, one of which, not necessarily taken at one stretch, should be in the field. To do this without extending the course it will be necessary to revise the type of training in the preclinical sciences, which here follows the pattern formerly in effect in the United Kingdom. Study should be made of the newer courses being introduced in the British medical schools and in the United States to get suggestions that might be helpful in revising the medical course in Nigeria to meet the needs of the country.

What should be done, it will be asked, about the highly gifted young student who is capable of reaching the top in any branch of medicine or medical science ?

By the end of the fifth year it should be possible, either by the ordinary examination or by special tests, to pick out such young scholars. Those falling into this category should be given the choice of going back into pure basic science, taking up one of the clinical specialties (also entailing extra modern scientific training), or taking further training in field and hospital medicine to fit them to serve as "field consultants." The latter should not be regarded as in any way "inferior in status" to the specialists in the narrower fields of medicine and surgery. It should be arranged that they could also obtain a higher diploma with its additional status, and stay in this new field of general practice which has been orientated to suit Nigerian conditions.

\section{Medical Ancillaries}

It would probably be best if the majority of medical ancillaries were women, but some males should certainly be recruited. Naturally one would try to obtain those with the best school records, but it is unlikely that the Higher School Certificate 
can be insisted upon if the required numbers are to be obtained. It would necessitate setting up a new type of training school, though, to begin with, both community nurses as at present trained and State-registered nurses should be eligible after a course of special training. Indeed, any intelligent young person who has had a basic nursing training could be very quickly orientated into the new ideas and duties envisaged in this reorganized Nigerian medical service.

We are aware that much homework would be necessary with the leaders and teachers of the nursing profession before the details were finally settled, but we see no insuperable difficulties here once the main principles have been accepted by the leaders of the medical profession and by the Federal and Regional Governments.

We feel that here is a field which the international health bodies such as W.H.O. and U.N.I.C.E.F., the great foundations, and the Government Aid Programmes should consider carefully, and, if convinced by our arguments, give assistance. Such assistance could take different forms, such as (1) aid in setting up and running special courses for the ancillary personnel described above, (2) help in the fields of communicable disease, nutrition, and community medicine, and (3) secondment of staff at all levels. Such help would be doubly valuable if a closer liaison existed between the postgraduate teachers in Great Britain and the other fully developed members of the Common- wealth and the developing countries, such as Nigeria. This could be accomplished by developing a two-way traffic, so that not only could students come from the developing countries to the centres of medical education in Britain, etc., but the teachers from these centres could visit countries such as Nigeria and adjust themselves to their conditions and needs.

We believe that the views expressed here are not only applicable to Nigeria but are important in all developing countries, particularly in Africa.

\section{Summary}

Nigeria has approximately 50 million people, fewer than 1,000 doctors in the field, and two medical schools which turn out under 100 doctors annually.

The population increase is approximately $2.9 \%$ annually. We propose a reorientation of medical education towards producing a doctor trained to supervise a wide area with the aid of ancillary personnel. We reject the second-class doctor or medical assistant, but suggest a medical course which will turn out a first-class doctor able to work in a wide field rather than the highly specalized product of most medical schools founded on Western lines. The type of ancillary personnel necessary is also discussed.

\section{CONFERENCES AND MEETINGS}

\section{British Association of Physical Medicine}

The Annual General Meeting of the British Association of Physical Medicine was held at the Guy's-New Cross Rehabilitation Unit, New Cross Hospital, S.E.14, on 10-12 March. The Annual Round was conducted by Dr. P. Hume Kendall, who showed cases of arteritis associated with rheumatoid arthritis. In a research forum a progress report was given on the projects which are being carried out in the Rehabilitation Unit. Dr. E. G. THRIFT demonstrated the presence of inclusion bodies in the polymorphonuclear leucocytes in synovial effusions, and considered that when they were present in more than half of the cells they were a useful diagnostic criterion for rheumatoid arthritis. Dr. Peter Robson described new techniques for evaluating neurological handicaps in new-born infants and reported that many patients with recognized established disability were receiving physiotherapy within the first few weeks of life. He emphasized that early treatment appreciably reduced the subsequent handicap in patients with cerebral palsy.

\section{Car Seats and Backache}

Mentioning that most people suffered from backache and sciatica when driving modern cars for long distances, Dr. Kendall reported a study into the design of car seats that is being carried out in the Rehabilitation Unit. He said that car seats were designed not with regard to the comfort of the body but rather for cheapness and to occupy the minimum amount of space. Inadequate support was given to the thighs or the trunk, and in cars with a firm, high-frequency suspension the seats frequently did not have enough " shock absorber" effect.

Dr. F. S. Cooksey, the President of the Association, described the results of the Multi-Centre Trial to study the effects of neck traction in cervical spondylosis (29 January, p. 253). The results not only indicated the correct place for traction in the course of the disease, but also gave much hitherto unreported knowledge of the natural history of cervical spondylosis. The unquestioned success of the trial, he pointed out, underlined the very definite need for the establishment of an academic unit or even an institute of physical medicine. There was a need for controlled scientific evaluation not only of the drugs used in treating the rheumatic disorders but also of all forms of physical therapy.

At the Annual Dinner held at the Royal College of Physicians, LoRd RoBens, Chairman of the Board of Governors of Guy's Hospital, said that the rheumatic diseases and disability following injury were some of the major causes of time lost in the coal-mining industry. The whole industrial world and the medical profession looked to the specialty of physical medicine to reduce the duration of incapacity that was associated with these conditions.

\section{Surgery in Rheumatoid Arthritis}

After the Annual Meeting a symposium on the place of surgery in rheumatoid arthritis was conducted by the President.
Dr. R. M. MAson said that the difference between orthopaedic surgery in rheumatoid arthritis compared with other fields was that the progress of the disease, both with regard to individual joints and the overall condition, could not be forecast at all. It was known, however, that the disability in four out of ten patients progressed steadily and relentlessly despite medical treatment, and it was in this group that surgery held out the most hope. Nevertheless, one should not expect surgeons to achieve the impossible by the direct approach to individual joints in what was a systemic disease.

Mr. O. J. VAUGHAN-JACKSON reported that once an erosion in a joint was demonstrable radiographically in the small joints of the hand, about half the joint had already been destroyed. Even slight damage to a few joints would result in a disproportionate amount of disability. Therefore surgical procedures on the fingers that offered even a limited range of improvement were often extremely valuable in helping to reduce disability. A gratifying increase in function of the upper limb might be expected after synovectomy of the elbow-joint, and an increase in the range of shoulder movements could usually be expected from a similar procedure.

Mr. W. A. Crabbe considered that osteotomy had little part to play in the treatment of severe rheumatoid arthritis of the hip-joint, and that replacement arthroplasty must be considered the treatment of choice. In the knee-joint total synovectomy combined with a tibial osteotomy frequently yielded spectacular and long-lasting success. 